\title{
Consensus statement understanding health and malnutrition through a systems approach: the ENOUGH program for early life
}

\author{
Jim Kaput • Ben van Ommen • Bas Kremer - Corrado Priami - Jacqueline Pontes Monteiro • \\ Melissa Morine $\cdot$ Fre Pepping $\cdot$ Zoey Diaz $\cdot$ Michael Fenech $\cdot$ Yiwu He $\cdot$ Ruud Albers • \\ Christian A. Drevon • Chris T. Evelo • Robert E. W. Hancock • Carel IJsselmuiden • \\ L. H. Lumey • Anne-Marie Minihane $\cdot$ Michael Muller $\cdot$ Chiara Murgia $\cdot$ Marijana Radonjic $\cdot$ \\ Bruno Sobral · Keith P. West Jr.
}

Received: 19 September 2013/ Accepted: 2 December 2013/Published online: 22 December 2013

(c) Springer-Verlag Berlin Heidelberg 2013

\begin{abstract}
Nutrition research, like most biomedical disciplines, adopted and often uses experimental approaches based on Beadle and Tatum's one gene-one polypeptide hypothesis, thereby reducing biological processes to single reactions or pathways. Systems thinking is needed to understand the complexity of health and disease processes requiring measurements of physiological processes, as well as environmental and social factors, which may alter the expression of genetic information. Analysis of physiological processes with omics technologies to assess systems' responses has only become available over the past decade
\end{abstract}

This study was conducted for the Participants of the Essential Nutrients Workshop.

Other individuals who attended the Essential Nutrients Workshop at Wageningen University contributed to the discussions that led to this manuscript: Lydia Afman (Wageningen University), Denis Barclay (Nestlé), Saskia de Pee (World Food Program), Terrence Forrester (University of West Indies), Henrik Friis (University of Copenhagen), Jamal Haidar (Addis Abba University), Mohamed Karmali (Public Health Agency-Canada), Albert Koulman (MRC Human Nutrition Research), Alida Melse (Wageningen University), Wim Saris (Maastricht University), Joe Tohme (HarvestPlus), Peter Weber (DSM), Michael Zimmermann (ETH Zurich).

\section{J. Kaput ( $\square)$}

Clinical Translation Unit, Nestle Institute of Health Sciences,

Lausanne, Switzerland

e-mail: James.Kaput@rd.nestle.com

B. van Ommen · B. Kremer · M. Radonjic

Research Group Microbiology and Systems Biology,

TNO, Zeist, The Netherlands

C. Priami - M. Morine

Department of Mathematics, University of Trento and The

Microsoft Research, University of Trento Centre for

Computational and Systems Biology, Rovereto, Italy and remains costly. Studies of environmental and social conditions known to alter health are often not connected to biomedical research. While these facts are widely accepted, developing and conducting comprehensive research programs for health are often beyond financial and human resources of single research groups. We propose a new research program on essential nutrients for optimal underpinning of growth and health (ENOUGH) that will use systems approaches with more comprehensive measurements and biostatistical analysis of the many biological and environmental factors that influence undernutrition. Creating a knowledge base for nutrition and health is a necessary first step toward developing solutions targeted to different populations in diverse social and physical environments for the two billion undernourished people in developed and developing economies.

Keywords Systems nutrition research - Malnutrition . Health · Essential nutrients for optimal · Underpinning of growth and health

\author{
J. P. Monteiro \\ Department of Pediatrics, Faculty of Medicine, \\ University of Sao Paulo, Ribeirão Prêto, Brazil \\ F. Pepping \\ Graduate School VLAG, Wageningen University, \\ Wageningen, The Netherlands \\ Z. Diaz - Y. He \\ Bill and Melinda Gates Foundation, Seattle, WA, USA \\ M. Fenech \\ Preventative Health Flagship, CSIRO, Adelaide, Australia
}




\section{Introduction}

Improving the nutritional health status of children and mothers in undernourished environments is essential for meeting the Millennium Development Goals (http://www. un.org/millenniumgoals/). Malnutrition is complex, multifaceted, and diverse in its health consequences, depending on extent, duration, and severity of coexisting deficiencies and comorbidities, and life stage of occurrence. An added complexity is the synergy between infection and malnutrition, articulated a half century ago (Scrimshaw et al. 1959): networks of interactions involving nutrients, pathogens, and host defense mechanisms can profoundly affect nutritional status, growth, and development. Genetic makeup and epigenetic mechanisms are increasingly recognized as determinants of metabolism and health both of which can be influenced by nutrition, pathogen exposure, and other environmental factors.

Significant progress (United Nations Standing Committee on Nutrition 2012) has been made in addressing the needs of populations with vitamin A, zinc, iron, iodine, and omega-3 fatty acids. Interventions focused on supplying single nutrients are unlikely to contribute significantly to optimizing the complex processes that maintain health and decrease or delay disease. Health may be defined as "the ability to adapt and self-manage" (Huber et al. 2011), a concept of metabolic health which has also been termed metabolic flexibility, or adaptability (Storlien et al. 2004). Environmental and nutritional factors contribute to metabolic flexibility and health: Inadequate nutritional status will probably reduce flexibility and increase susceptibility

\section{R. Albers}

NutriLeads, Rockanje, The Netherlands

R. Albers

Host Microbe Interactomics Group, Wageningen University,

Wageningen, The Netherlands

C. A. Drevon

Department of Nutrition, Faculty of Medicine, Institute of Basic

Medical Sciences, University of Oslo, Oslo, Norway

C. T. Evelo

Department of Bioinformatics, Maastricht University,

Maastricht, The Netherlands

R. E. W. Hancock

Department of Microbiology and Immunology,

University of British Columbia, Vancouver, BC, Canada

C. IJsselmuiden

Council on Health Research for Economic Development,

Geneva, Switzerland

L. H. Lumey

Department of Epidemiology, Mailman School of Public Health, Columbia University, New York, NY, USA to chronic disease and infectious agents. The current biological knowledge for assessing the status and needs for essential nutrients is inadequate. Combining comprehensive measurements of individual and environmental variables with systems experimental strategies may confer deep insight into metabolic networks, modifiable by nutrients and physical activity, enabling new approaches of attaining personal and public health.

\section{Physiological, cognitive, and immunological consequences related to nutritional status}

A body of research has begun to demonstrate the effects of macronutrient and essential nutrient intakes and status on metabolic and cognitive development (Dewey and Begum 2011). Malnutrition during pregnancy, lactation, and early life can impair multiple facets of the health of mothers and offspring and may cause epigenetic changes promoting chronic effects on metabolism and susceptibility to disease (Khulan et al. 2012). Among other mechanisms, DNA damage due to defective DNA replication and repair processes (Fenech 2004, 2010) and the impaired capacity to differentiate and grow new cells may contribute to low birth weight, stunting, underweight, and inadequate cognitive development.

Cognitive development is impaired as a consequence of protein and micronutrient malnutrition. Methods for assessing cognitive function in infants (Westerberg et al. 2011) and analyzing first-year growth patterns of low birth weight babies have been developed and tested in nutrition

A.-M. Minihane

Nutrigenetics Program, Norwich Medical School,

University of East Anglia, Norwich, UK

M. Muller

Nutrition, Metabolism \& Genomics Group, Wageningen

University, Wageningen, The Netherlands

C. Murgia

Nutritional Science, Institute Nazionale di Ricerca per gli

Alimenti e la Nutrizione (INRAN), Rome, Italy

B. Sobral

BioSystem Informatics Unit, Nestle Institute of Health Sciences,

Lausanne, Switzerland

K. P. West Jr.

Center for Human Nutrition, Johns Hopkins Bloomberg School of Public Health, Baltimore, MD, USA 
intervention studies (Westerberg et al. 2010). Among these methods are the visual event response-related potentials (VERP (Braddick et al. 2011)) and MRI technologies to study brain development in response to nutritional intakes. Although these methods are currently in use in sophisticated settings, efforts would be initiated to develop systems for use in developing countries.

Immune dysfunction may contribute to the high burden of infectious mortality in malnourished children as seen in many poor and unhygienic environments (McKay et al. 2010; Verkerke et al. 2012). Deficiencies in a number of essential nutrients may impact the innate and adaptive immune system, and supplementation may improve immune responses (Wintergerst et al. 2007; Maggini et al. 2007; Savy et al. 2009) depending on genetic makeup and life stage. Malnourishment affects the efficiency of oral vaccines, e.g., cholera (Levine 2010), but does not consistently impair the response to parenteral vaccinations (Savy et al. 2009). This difference implies that the impaired response is related to aberrant function of the gastrointestinal tract, the microbiome, and/or the local mucosal immune system, rather than a general physiological inability to respond to vaccines (Levine 2010). Nutritional supplementation may improve immune responses depending on genetic makeup and life stages of the intervention and outcome (Maggini et al. 2007).

Gastrointestinal function and integrity also play an important role in growth failure and immune function. Earlychildhood diarrhea is linked to increased risk of chronic diseases later in life-the so-called triple burden of impaired gut function (Guerrant et al. 2012). Little is known about the human microbial ecology, how it changes due to suboptimal nutrition, and how the altered microbiome may influence metabolism, cognitive functions, and immune response. The importance of gut integrity is revealed by small intestinal (or bowel) bacterial overgrowth (SIBO or SBBO), which is associated with failure to thrive and slow growth (Bures et al. 2010; Korpe and Petri 2012). SBBO also occurs in environments with poor sanitation and contaminated water (Korpe and Petri 2012) called environmental enteropathy (EE) (McKay et al. 2010). The morphological changes in EE are associated with maldigestion, malabsorption of nutrients, and increased intestinal permeability.

Human populations are exposed to a broad range of access to nutritious foods and socioeconomic conditions in low-, transitional-, and high-income countries. Undernourishment is inversely correlated with per capita income which differs within and between rural and urban settings (United Nations Standing Committee on Nutrition 2012), countries, and regions (Gallagher 2006). The consequences are that the physiological and psychological consequences to suboptimal levels of essential nutrients in combination with different environmental conditions have not been well studied in neither developing nor developed regions of the world.
The slow application of systems thinking to biomedical research

Among the great advances of twentieth and twenty-first century science were the discovery and elucidation of biochemical reactions and pathways. Information from analysis of isolated pathways was combined into seemingly comprehensive metabolic and signal transduction maps like the KEGG pathway maps (http://www.genome. $\mathrm{jp} / \mathrm{kegg} /$ pathway). Measured or predicted changes in specific reactions or pathways are often used to explain health and disease processes. The information embedded in these representations was often derived from research on disease rather than from understanding biological processes. Conventional understanding conveyed in these maps provided not only the basis for designing nutrition experiments and intervention programs (see Table 1), leaving response effects to be inferred based on changes in a few biochemical, physiological, functional, or clinical outcomes (Darnton-Hill et al. 2009). The simple visual figures of biochemical transformations have led to "the illusion of explanatory depth" (Rozenblit and Keil 2002). That is, these maps do not provide an understanding of how and why an organism functions or responds because biological processes are highly complex, interactive, and dynamic due to interactions within and between cells and organs and because these processes are constantly interacting with environmental factors. Using a single biochemical pathway as the benchmark for the effects of nutrient deficiency and supplementation will not explain the system's response.

We now understand that pathways interact with regulatory elements, with one another, and with systems critical to the endocrine, circulatory, digestive, nervous, and immune function (Afacan et al. 2012; MacLellan et al. 2012; Slikker et al. 2007; van Ommen et al. 2008a, b; Zhao et al. 2012). As an example, a map of the central immunity pathway linking the toll-like receptor 4 to the transcription factor $\mathrm{NFKB}$ (a master regulator responsive to nutrients) contains only 20 core components, but adding just the main interacting elements of these 20 core proteins expands the network to more than 800 proteins (Gardy et al. 2009).

Several current systems biology treatises are technological extensions of the general systems theory for biology first proposed by von Bertalanffy more than 60 years ago (von Bertalanffy 1951). Modern views of systems biology concepts (Hood et al. 2004) propose an holistic approach relying on:

1. Global quantitative measures on the genome, transcriptome, proteome; metabolome, and/or cytome levels are usually based on high-throughput technologies. 
Table 1 Common practices in malnutrition research

Frank deficiencies of the micronutrients (especially vitamin A, zinc, iron, iodine, folate, vitamin D) are prevalent globally. The success of preventing rickets (vitamin D), beriberi (thiamine), scurvy (vitamin C), and pellagra (niacin) justified interventions of single or a few nutrients in malnourished individuals. Major successes have been achieved in delivering specific micronutrients to needy populations. However, the impact of subclinical undernourishment and the needs of populations in different environments and with diverse cultural, genetic, and agricultural histories are unknown. Several limitations have become apparent in nutrition research as well as other healthrelated projects including

Experimental interventions in which one or at most a few nutrients are used for interventions, with notable exceptions such as http://ilins.org and (Darnton-hill et al. 2009). Only a small number of parameters were usually monitored, novel computational analyses were not used, resources for integrative approaches were lacking, and research funding culture continues to promote individual laboratories rather than collaborative consortia (other factors can also contribute)

Use of single biomarkers has often become the "gold standard" in essential nutrient research, underestimating the complexity of biological processes. Many biomarkers are poor predictors of health, growth and development, immune function, and cognitive ability

The failure of assessing "context or environment" in research and subsequent nutrient interventions. For example, the effects of malaria (Afacan et al. 2012), assessment of and need for interacting nutrients (Zimmermann and Kohrle 2002), presence of environmental contaminants (e.g., lead) (Zimmermann et al. 2006), differences in food matrix (Moretti et al. 2006), microbiotic diversity (Gordon et al. 2012), culture, and other factors may alter nutrient bioavailability and biological functions

Genetic, epigenetic, microbiome, diet, and environmental and cultural diversity have not been sufficiently integrated in nutrition research

2. Measures over time in homeostatic and challenged states, allowing metabolic flux analyses.

3. Integration and (meta-) analyses of data with computational network biology methods.

4. Modeling to unravel mechanistic relationships of the biological processes.

The crucial missing factors from many system biology definitions and experimental approaches are the influence and measures of environment such as diet, physical activity and other lifestyle factors, and psychosocial factors, each of which may influence expression of genes, levels of proteins and metabolites and may promote mutagenic effects. For example, seasonal differences in nutrient availability were consistently associated with changes in blood concentrations of one-carbon metabolites and cofactors, resulting in altered epigenetic potential (Dominguez-Salas et al. 2013). Hence, experimental designs and approaches should incorporate more comprehensive assessment of biospecimens but also exposures to environmental factors. The results of combining such data and approaches will provide novel insight into mechanisms, complex biomarkers, but most importantly, an understanding of health beyond disease-specific symptoms (heart disease versus whole organism physiology associated with diet and lifestyle).

\section{Conceptual framework of systems nutrition}

Systems thinking is starting to influence nutritional (Morine et al. 2010, 2011, 2012) and immunological (Afacan et al. 2012) research although significant challenges remain in adapting and applying these advances to human studies (Norheim et al. 2012). Capturing a wider range of quantitative environmental and physiological measures like sleep, physical activity, psychology, healthcare disparities, and differences in social status (Kaput et al. 2005) (Fig. 1) are still difficult primarily due to a lack of tools (Stumbo et al. 2010; Tucker et al. 2013), resources, and transdisciplinary approaches. More integrative methods for health description (van der Greef et al. 2010; van Wietmarschen et al. 2011) and for incorporating biopsychosocial factors influencing biological processes (Berry 2011) may improve phenotypic characterization. Translational research models such as community-based participatory research (McCabeSellers et al. 2008) implicitly incorporate environmental variables, although lack of expertise and resources often precludes proper capture of important "contextual" or metadata variables.

The influence of genetic diversity has also not been assessed when analyzing the response to nutritional intervention. Although analysis of common ( $>1 \%$ frequency) variants is increasingly used in nutrition research (Merched and Chan 2013), genome sequencing projects demonstrate that all individuals encode unique variations (Consortium 2012) undetected by array technologies. These new variants may occur in any biological pathway including those expected to alter physiological processes or response to nutritional variables (Morine et al. 2010, 2011).

A major challenge for implementing and using systems approaches may be to assure sufficient and accurate quantitative data from the individual, family, and community levels with data standards adopted across studies. Assessing many factors and stressors that affect physiological processes will be a significant challenge since food and nutrition security is a complex system resulting from interrelationships between societal, legal, and economic factors spanning the farm to fork trajectory (Hammond and Dubé 2012). Nevertheless, data harmonization of each level of these multi-scale networks will enable integration 


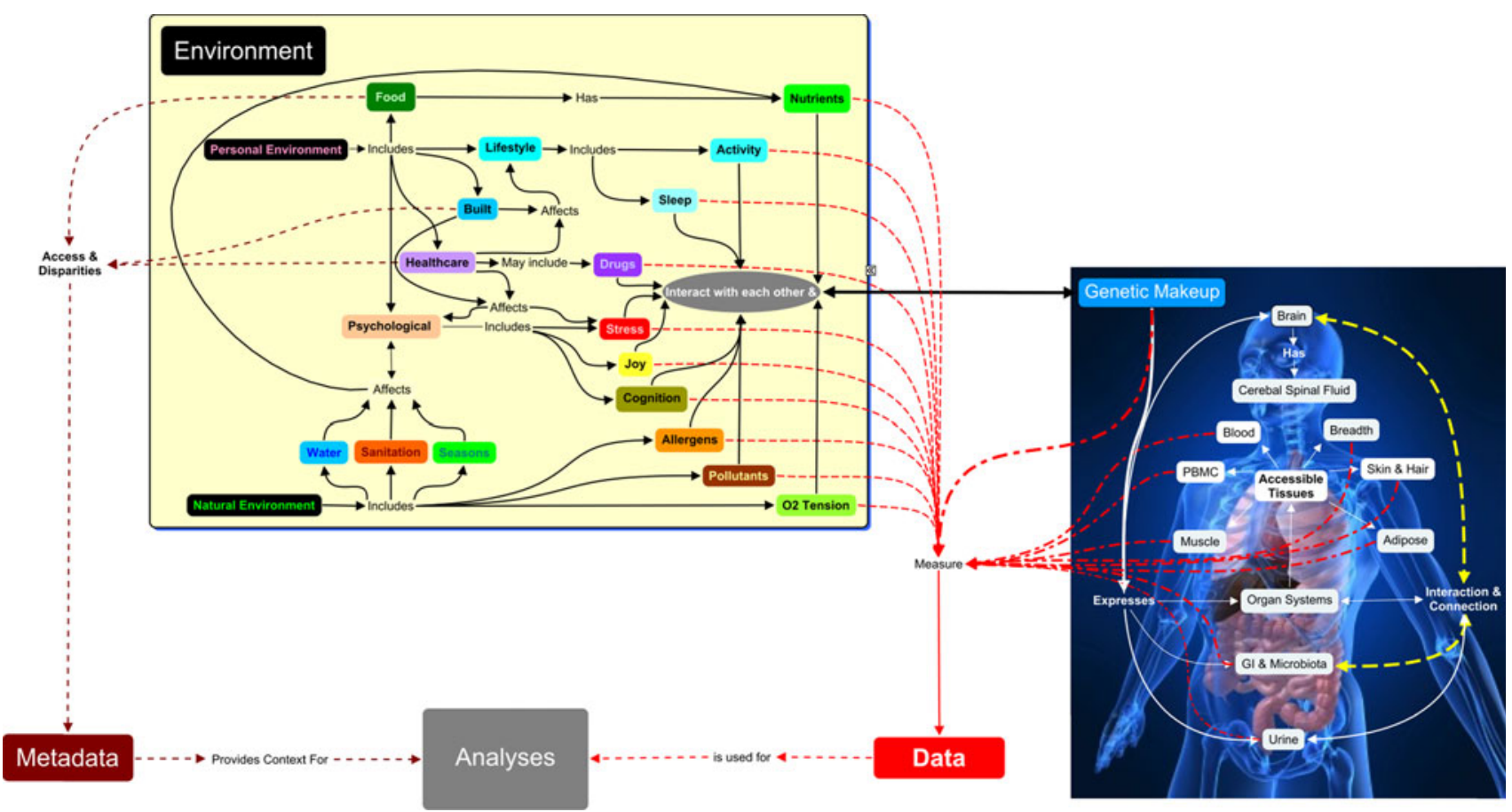

Fig. 1 Examples of experimental variables for systems nutrition research. Reductionistic approaches typically focus on measures of physiology (human on the right) and one or a few environmental variables (left). Some variables may represent both input and output of the human system, and some output variables may affect other input variables (e.g., stress effect on diet). The input of systems nutrition research would capture and conceptually organize those

from different studies for exploratory, diagnostic, and predictive computational modeling. Integration of genomic information with clinical, extensive physiological data, and metadata (individual patient exposures and status measures that affect health) is spawning new bioinformatics approaches that have yet to mature.

The importance of capturing, managing, storing, and analyzing high-dimensional nutritional data and its associated metadata have been the subject of several reviews (Kaput et al. 2006; Kibbe 2006; van Ommen et al. 2010a; Stumbo et al. 2010; Lynn et al. 2010; Breuer et al. 2012) and the development of databases such as InnateDB (Lynn et al. 2010; Breuer et al. 2012) and the modular Nutritional Phenotype (dbNP) data infrastructure (van Ommen et al. 2010a). Data harmonization (van Ommen et al. 2010a; Lynn et al. 2010) is essential for enabling systems approaches to analysis of high-dimensional data. Networkbased models describing health, subsystems of physiological processes, and pathological states (Morine and Priami 2013; Mayer et al. 2013) provide the foundation for developing these system-based models:

- Collect high-quality, high-dimensional genomic, proteomic, and/or metabolomics data with appropriate filtering from prospective and intervention studies. environmental variables that alter physiological variables, as well as comprehensive analyses of physiological processes. Some environmental variables may be challenging to quantify (e.g., the built environment) but may be recorded as metadata associated with the experimental results and important for interpretation of the data. This figure describes primarily the data that may be captured for analyses, and a separate process captures the analysis pipeline

- Computational definition of systems networks and subnetworks associated with health and pathologies and the underlying pathways, functional attributes, and mechanisms.

- Definition of biomarkers as hubs and bottlenecks connecting to different network elements of importance in signal transduction.

- Network simulations and flux analyses to unravel physiological and pathological states and the impact of interventions.

- Simulations integrating molecular interactions and correlations.

- Computational predictions and actionable knowledge.

The first models of cellular responses, organs, systems, or conditions can be used as a "wind tunnel" for testing and designing intervention studies. Data from model organisms may provide an initial (tissue-specific) framework, describing in molecular detail, the processes of transport, metabolism and signaling in steady state, as well as during challenges with altered diet, physical activity, fasting, and sleeping (van Ommen et al. 2009).

The goal of systems nutrition (Fairweather-Tait 2003; van Ommen et al. 2008a, 2009; de Graaf et al. 2009; Morine et al. 2010, 2011, 2012; Fu et al. 2011), systems 


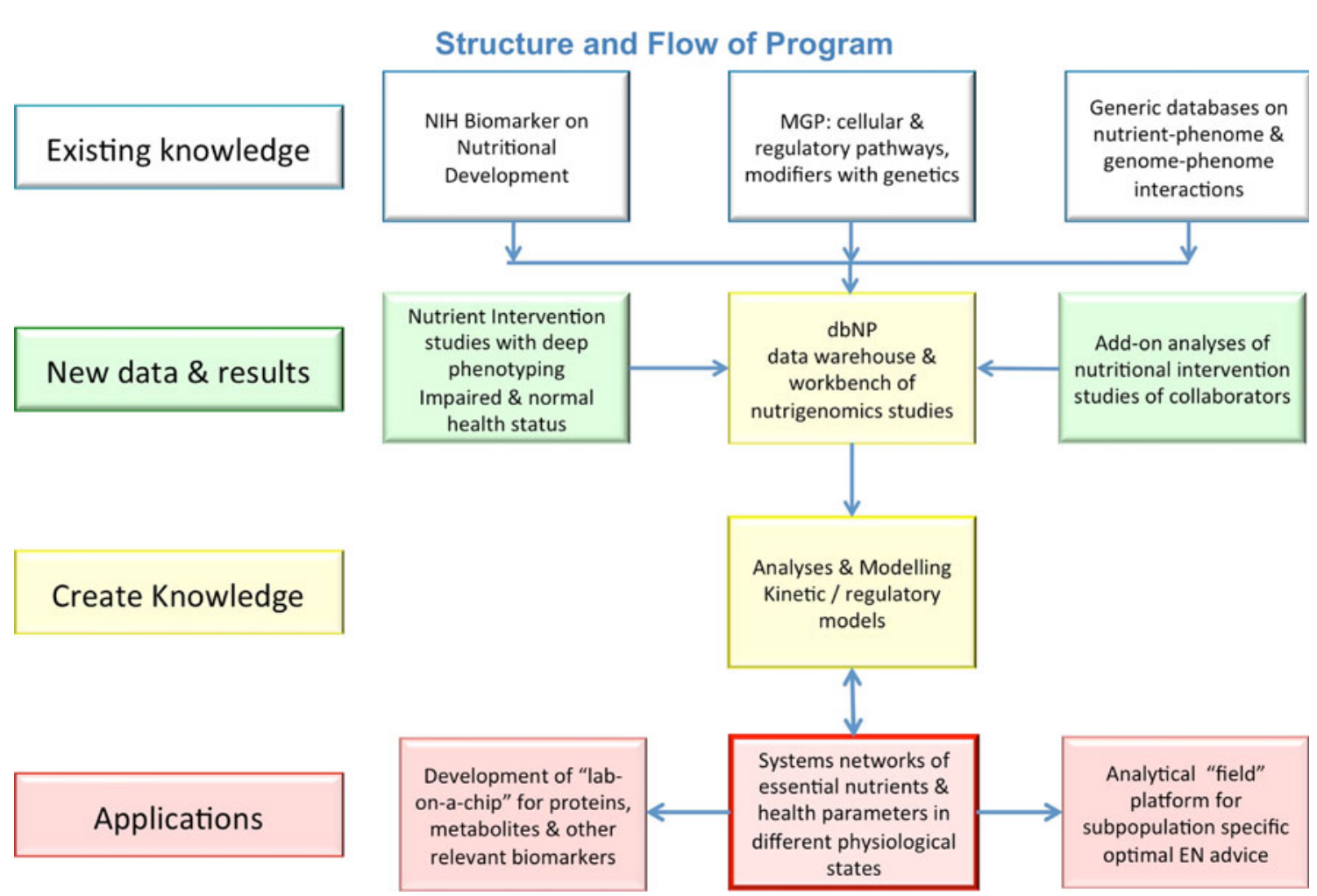

Fig. 2 Flow of essential nutrients for optimal underpinning of growth and health (ENOUGH). The NuGO-led consortium will use existing knowledge from international efforts to develop a systems approach to malnutrition research (existing knowledge). Data from existing or

immunology (Afacan et al. 2012), and systems analysis (Palsson 2006) can be applied to malnutrition research specifically to:

Improve the design and implementation of multiscale interventions studies for environmental enteropathies, related growth, immune- and learning disorders, and essential nutrient deficiencies.

\section{The next steps}

NuGO (http://www.nugo.org) has initiated development of a collaborative, open data sharing, systems nutrition research program named ENOUGH (essential nutrients for optimal underpinning of growth and health) focused on individuals in undernourished populations (Fig. 2). ENOUGH builds on the ongoing international effort of examining malnutrition and continues collaborations on knowledge building with the US NIH BOND project (Brabin et al. 2011) and international efforts like EURRECA (http://www.eurreca.org/), and the NuGO-led Micronutrient Genomics Project (MGP) (van Ommen et al. 2010b).

ENOUGH (Fig. 2) will go beyond simply measuring metabolites in body fluids (so-called helicopter research; new projects will be integrated in the Phenotype database or InnateDB or some combination (new data and results). Analysis of these data will provide knowledge with applications for improving personal and public health

Glenn, 2006; Horowitz et al. 2009) to include engagement of community members (Tindana et al. 2007; Cohen et al. 2008; McCabe-Sellers et al. 2008; Horowitz et al. 2009). Active participatory research will promote comprehensive analyses and incorporate an understanding of local customs, conditions, and factors affecting nutrient accessibility. A challenge for international research projects is the patchwork rules and regulations for human study research (see (Seguin et al. 2008; Office for Human Research Protections 2012)). Nutrigenomics projects involving children, genetic analysis, physiological and environmental measurements, and international collaboration raise ethical questions. Although an effort to build research ethics review capacity in low- and middle-income countries has been initiated, intervention studies raise ethical problems for which few research ethics committees globally are prepared to act on. The Council on Health Research for Economic Development (COHRED) has developed and hosts a Health Research Web (http://www.healthresearchweb.org/) to foster interaction between research partners in different countries. A major aspect of their effort is the creation of tools for facilitating reviews by collaborating centers with distinct research ethics committees (aka institutional review boards (http://www.healthresearchweb.org/en/regulation and_ethics_review_of_research)). 
ENOUGH will contribute through scientific research to the building of local capacity and infrastructure by engaging governments, agencies, and communities (McCabe-Sellers et al. 2008), a process consistent with the goals of North-South knowledge and technology transfer (Singer and Daar 2001; Daar et al. 2007; Taylor et al. 2007; Séguin et al. 2008) and stimulation of economic development by research activities (www.cohred.org; Bhan et al. 2007). These collaborative research strategies may improve translation of basic research to local societies. One example of this capacity building is the Human Variome Project, aiming to understand the genetic basis of human diseases in developed and developing countries (Patrinos et al. 2010; Al Aama et al. 2011).

The availability of healthy and affordable food and clean water is essential for health. In addition, nutrient composition targeted to genetic and cultural conditions can now be analyzed and optimized. Malnutrition is a complex condition, which will be unresolved by systems nutrition research alone, but the multifaceted solutions to address this global problem require evidence from experimental studies, which acknowledge, measure, and analyze the gene-environment factors contributing to dysfunctional growth, metabolic, and cognitive processes. Research focused on the analysis and understanding of nutritional needs can contribute significantly to the continuation of international collaboration and implementation of systems concepts in academia, governments, industry, and NGOs. Only by combined efforts will the Millennium Development goals of improving nutrition, health, and the lives of women and children be reached.

Acknowledgments This manuscript emerged from a workshop entitled A Systems Nutrition Approach to Essential Nutrients (Wageningen, The Netherlands. 7-9 November 2012). The aim of the meeting was to discuss whether systems biology approaches could contribute to research on essential nutrient malnutrition. Participants (author status) from the fields of systems biology, omics technologies, ethics, capacity building, immunity, and international nutrition contributed to the workshop. Discussions focused on the related topics of immune function and infectious disease susceptibility in the malnourished, metabolic health including growth and cognitive function, bioinformatics needs and computational methods for system analysis, ethics, and sustainability. The workshop was cosponsored by the Bill and Melinda Gates Foundation, the Nestle Institute of Health Sciences, DSM, The Microsoft Research-University of Trento Institute of Computational and Systems Biology (COSBI), Wageningen University, and NuGO. The funders had no role in study design, data collection and analysis, decision to publish, or preparation of the manuscript. JK and BS are employed by Nestle Institute of Health Sciences, a for-profit NESTEC company. However, no specific funding was provided for this work except for the sponsorship of the workshop. RAH is the Canada Research Chair and is funded by the Canadian Institutes for Health Research. BK, MR, and $\mathrm{BvO}$ are employed by TNO, a not-for-profit organization regulated by public law. TNO is an independent research organization dealing with health-related research, not part of any government, university or company. The organization may benefit from its knowledge, by supporting companies in their product development by consultancy and research. In these cases, the authors will not receive additional salary, additional personal income, or any form of financial support.

Conflict of interest The following authors work for private or public companies: RA (NutriLeads), JK, and BS (Nestle Institute of Health Sciences). RAH is developing new treatments for infectious and inflammatory conditions and has patented and out-licensed such treatments.

Ethical standards This article does not contain any studies with human or animal subjects performed by the any of the authors.

\section{References}

Al Aama J, Smith TD, Lo A et al (2011) Initiating a Human Variome Project Country Node. Hum Mutat 32:501-506. doi:10.1002/ humu. 21463

Afacan NJ, Fjell CD, Hancock REW (2012) A systems biology approach to nutritional immunology: focus on innate immunity. Mol Aspects Med 33:14-25. doi:10.1016/j.mam.2011.10.013

Berry EM (2011) The role of the sociotype in managing chronic disease: integrating bio-psycho-sociology with systems biology. Med Hypotheses 77:610-613. doi:10.1016/j.mehy.2011.06.046

Bhan A, Singh J, Upshur R et al (2007) Grand challenges in global health: engaging civil society organizations in biomedical research in developing countries. PLoS Med 4:e272. doi:10. 1371/journal.pmed.0040272

Brabin B, Combs G Jr, Abbe MRL, et al (2011) Executive summary: biomarkers of nutrition for development: building a consensus 1-3. doi:10.3945/ajcn.110.008227.Am

Braddick O, Atkinson J, Wattam-Bell J (2011) VERP and brain imaging for identifying levels of visual dorsal and ventral stream function in typical and preterm infants. Prog Brain Res 189:95-111. doi:10.1016/B978-0-444-53884-0.00020-8

Breuer K, Foroushani AK, Laird MR et al (2012) InnateDB: systems biology of innate immunity and beyond-recent updates and continuing curation. Nucleic Acids Res. doi:10.1093/nar/ gks1147

Bures J, Cyrany J, Kohoutova D et al (2010) Small intestinal bacterial overgrowth syndrome. World J Gastroenterol 16:2978-2990

Cohen ER, Masum H, Berndtson K et al (2008) Public engagement on global health challenges. BMC Public Health 8:168. doi:10. 1186/1471-2458-8-168

Consortium T 100 GP (2012) An integrated map of genetic variation from 1,092 human genomes. Nature 491:56-65. doi:10.1038/ nature 11632

Daar AS, Berndtson K, Persad DL, Singer PA (2007) How can developing countries harness biotechnology to improve health? BMC Public Health 7:346. doi:10.1186/1471-2458-7-346

Darnton-hill I, Schultink W, Shrimpton R et al (2009) Multiple Micronutrient Supplementation During Pregnancy in Developing Country Settings. In: Dalmiya N, Darnton-Hill I, Schultink W, Shrimpton R (eds) Food Nutr. Bull. pp 1-100

Dewey KG, Begum K (2011) Long-term consequences of stunting in early life. Matern Child Nutr 7(Suppl 3):5-18. doi:10.1111/j. 1740-8709.2011.00349.x

Dominguez-Salas P, Moore SE, Cole D et al (2013) DNA methylation potential : dietary intake and blood concentrations of one-carbon metabolites and cofactors in rural African women. Am J Clin Nutr 97:1217-1227. doi:10.3945/ajcn.112.048462.The

Fairweather-Tait SJ (2003) Human nutrition and food research: opportunities and challenges in the post-genomic era. Philos Trans R Soc L B Biol Sci 358:1709-1727 
Fenech M (2004) Genome health nutrigenomics: nutrition and the science of optimal genome maintenance. Asia Pac J Clin Nutr 13:S15

Fenech MF (2010) Dietary reference values of individual micronutrients and nutriomes for genome damage prevention : current status and a road map to the. Am J Clin Nutr 91:1438-1454. doi:10.3945/ajen.2010.28674D.1

Fu W, Stromberg A, Viele K et al (2011) NStatistics and bioinformatics in nutritional scienes: analysis of complex data in the era of systems biology. J Nutr Biochem 21:561-572. doi:10.1016/j. jnutbio.2009.11.007.Statistics

Gallagher M (2006) FOOD DESERTS. http://www.marigallagher. com/site_media/dynamic/project_files/Chicago_Food_Desert_ Report.pdf

Gardy JL, Lynn DJ, Brinkman FSL, Hancock REW (2009) Enabling a systems biology approach to immunology: focus on innate immunity. Trends Immunol 30:249-262. doi:10.1016/j.it.2009. 03.009

Glenn D (2006) Blood feud: a controversy over South American DNA samples held in North American laboratories ripples through anthropology. Chron High Educ 52(A14-6):A18

Gordon JI, Dewey KG, Mills D a, Medzhitov RM (2012) The human gut microbiota and undernutrition. Sci Transl Med 4:137ps12. doi:10.1126/scitranslmed.3004347

De Graaf AA, Freidig AP, De Roos B et al (2009) Nutritional systems biology modeling: from molecular mechanisms to physiology. PLoS Comput Biol 5:e1000554

Van der Greef J, van Wietmarschen H, Schroën J et al (2010) Systems biology-based diagnostic principles as pillars of the bridge between Chinese and Western medicine. Planta Med 76:2036-2047. doi:10.1055/s-0030-1250450

Guerrant RL, Deboer MD, Moore SR et al (2012) The impoverished gut-a triple burden of diarrhoea, stunting and chronic disease. Nat Rev Gastroenterol Hepatol. doi:10.1038/nrgastro.2012.239

Hammond RA, Dubé L (2012) A systems science perspective and transdisciplinary models for food and nutrition security. Proc Natl Acad Sci USA 109:12356-12363. doi:10.1073/pnas. 0913003109

Hood L, Heath JR, Phelps ME, Lin B (2004) Systems biology and new technologies enable predictive and preventative medicine. Science (80) 306:640-643

Horowitz CR, Robinson M, Seifer S (2009) Community-based participatory research from the margin to the mainstream: are researchers prepared? Circulation 119:2633-2642. doi:10.1161/ CIRCULATIONAHA.107.729863

Huber M, Knottnerus JA, Green L et al (2011) How should we define health? BMJ 343:d4163. doi:10.1136/bmj.d4163

Kaput J, Astley S, Renkema M et al (2006) Harnessing Nutrigenomics: development of web-based communication, databases, resources, and tools. Genes Nutr 1:5-11. doi:10.1007/BF0 2829931

Kaput J, Ordovas JM, Ferguson L et al (2005) The case for strategic international alliances to harness nutritional genomics for public and personal health. Br J Nutr 94:623-632

Khulan B, Cooper WN, Skinner BM et al (2012) Periconceptional maternal micronutrient supplementation is associated with widespread gender related changes in the epigenome: a study of a unique resource in the Gambia. Hum Mol Genet 21:2086-2101. doi:10.1093/hmg/dds026

Kibbe WA (2006) The Informatics and Bioinformatics Infrastructure of a Nutrigenomics Database. In: Kaput Rodriguez, R.L. J (ed) Nutr. Genomics. Discov. Path to Pers. Nutr. Wiley, Hoboken, NJ, pp 353-374

Korpe PS, Petri WA (2012) Environmental enteropathy: critical implications of a poorly understood condition. Trends Mol Med 18:328-336. doi:10.1016/j.molmed.2012.04.007
Levine MM (2010) Immunogenicity and efficacy of oral vaccines in developing countries: lessons from a live cholera vaccine. BMC Biol 8:129. doi:10.1186/1741-7007-8-129

Lynn DJ, Chan C, Naseer M et al (2010) Curating the innate immunity interactome. BMC Syst Biol 4:117. doi:10.1186/17520509-4-117

MacLellan WR, Wang Y, Lusis AJ (2012) Systems-based approaches to cardiovascular disease. Nat Rev Cardiol 9:172-184. doi:10. 1038/nrcardio.2011.208

Maggini S, Wintergerst ES, Beveridge S, Hornig DH (2007) Selected vitamins and trace elements support immune function by strengthening epithelial barriers and cellular and humoral immune responses. Br J Nutr 98(Suppl 1):S29-S35. doi:10. 1017/S0007114507832971

Mayer ML, Blohmke CJ, Falsafi R et al (2013) Rescue of dysfunctional autophagy attenuates hyperinflammatory responses from cystic fibrosis cells. J Immunol 190:12271238. doi:10.4049/jimmunol.1201404

McCabe-Sellers B, Lovera D, Nuss H et al (2008) Personalizing nutrigenomics research through community based participatory research and omics technologies. OMICS 12:263-272. doi:10. 1089/omi 2008.0041

McKay S, Gaudier E, Campbell D, Prentice A (2010) Environmental enteropathy: new targets for nutritional interventions. Int Health 2:172-180

Merched AJ, Chan L (2013) Nutrigenetics and nutrigenomics of atherosclerosis. Curr Atheroscler Rep 15:328. doi:10.1007/ s11883-013-0328-6

Moretti D, Zimmermann MB, Wegmuller R et al (2006) Iron status and food matrix strongly affect the relative bioavailability of ferric pyrophosphate in humans. Am J Clin Nutr 83:632-638

Morine MJ, McMonagle J, Toomey S et al (2010) Bi-directional gene set enrichment and canonical correlation analysis identify key diet-sensitive pathways and biomarkers of metabolic syndrome. BMC Bioinformatics 11:499. doi:10.1186/1471-2105-11-499

Morine MJ, Priami C (2013) Analysis of biological systems. Imperial College Press, London (in press)

Morine MJ, Tierney AC, van Ommen B et al (2011) Transcriptomic coordination in the human metabolic network reveals links between n-3 fat intake, adipose tissue gene expression and metabolic health. PLoS Comput Biol 7:e1002223. doi:10.1371/ journal.pcbi. 1002223

Morine MJ, Toomey S, McGillicuddy FC et al (2012) Network analysis of adipose tissue gene expression highlights altered metabolic and regulatory transcriptomic activity in high-fat-dietfed IL-1RI knockout mice. J Nutr Biochem. doi:10.1016/j. jnutbio.2012.04.012

Norheim F, Gjelstad IMF, Hjorth M et al (2012) Molecular nutrition research: the modern way of performing nutritional science. Nutrients 4:1898-1944. doi:10.3390/nu4121898

Office for Human Research Protections (2012) International compilation of human research standards. 114

Palsson BO (2006) Systems biology: properties of reconstructed networks. 322

Patrinos G, Al Aama J, Al Aqeel A et al (2010) Recommendations for genetic variation data capture in developing countries to ensure a comprehensive worldwide data collection. Hum Mutat 31:1-8

Rozenblit L, Keil F (2002) The misunderstood limits of folk science: an illusion of explanatory depth. Cogn Sci 26:521-562. doi:10. $1207 / \mathrm{s} 15516709 \operatorname{cog} 26051$

Savy M, Edmond K, Fine PEM et al (2009) Landscape analysis of interactions between nutrition and vaccine responses in children. J Nutr 139:2154S-2218S. doi:10.3945/jn.109.105312.research

Scrimshaw N, Taylor C, Gordon J (1959) Interactions of nutrition and infection. Am J Med Sci 237:367-403 
Séguin B, Hardy B-J, Singer PA, Daar AS (2008) Genomics, public health and developing countries: the case of the Mexican National Institute of Genomic Medicine (INMEGEN). Nat Rev Genet 9(Suppl 1):S5-S9. doi:10.1038/nrg2442

Seguin B, Hardy BJ, Singer PA, Daar AS (2008) Genomic medicine and developing countries: creating a room of their own. Nat Rev Genet 9:487-493. doi:10.1038/nrg2379

Singer PA, Daar AS (2001) Harnessing genomics and biotechnology to improve global health equity. Science (80) 294:87-89

Slikker W Jr, Paule MG, Wright LK et al (2007) Systems biology approaches for toxicology. J Appl Toxicol 27:201-217. doi:10. 1002/jat. 1207

Storlien L, Oakes ND, Kelley DE (2004) Metabolic flexibility. Proc Nutr Soc 63:363-368. doi:10.1079/PNS2004349

Stumbo PJ, Weiss R, Newman JW et al (2010) Web-enabled and improved software tools and data are needed to measure nutrient intakes and physical activity for personalized health research. J Nutr 140:2104-2115. doi:10.3945/jn.110.128371

Taylor AD, Brook D, Watters D et al (2007) North-south partnerships-a study of Canadian firms. Nat Biotechnol 25:978-979. doi:10.1038/nbt0907-978

Tindana PO, Singh JA, Tracy CS et al (2007) Grand challenges in global health: community engagement in research in developing countries. PLoS Med 4:e273. doi:10.1371/journal.pmed.0040273

Tucker KL, Smith CE, Lai C-Q, Ordovas JM (2013) Quantifying diet for nutrigenomic studies. Annu Rev Nutr 33:349-371. doi:10. 1146/annurev-nutr-072610-145203

United Nations Standing Committee on Nutrition (2012) What progress in nutrition? Nutr Rev 5:134. doi:10.1111/j.17534887.1947.tb04238.x

Van Ommen B, Cavallieri D, Roche HM et al (2008a) The challenges for molecular nutrition research 4: the "nutritional systems biology level". Genes Nutr 3:107-113. doi:10.1007/s12263-0080090-5

Van Ommen B, Fairweather-Tait S, Freidig A et al (2008b) A network biology model of micronutrient related health. Br J Nutr 99(Suppl 3):S72-S80. doi:10.1017/S0007114508006922

Van Ommen B, Keijer J, Heil SG, Kaput J (2009) Challenging homeostasis to define biomarkers for nutrition related health. Mol Nutr Food Res 53:795-804. doi:10.1002/mnfr.200800390
Van Ommen B, Bouwman J, Dragsted LO et al (2010a) Challenges of molecular nutrition research 6: the nutritional phenotype database to store, share and evaluate nutritional systems biology studies. Genes Nutr 5:189-203. doi:10.1007/s12263-010-0167-9

Van Ommen B, El-Sohemy A, Hesketh J et al (2010b) The micronutrient genomics project: creating a community driven knowledge base for micronutrient research. Genes Nutr 5:285-296

Van Wietmarschen HA, Reijmers TH, van der Kooij AJ et al (2011) Sub-typing of rheumatic diseases based on a systems diagnosis questionnaire. PLoS One 6:e24846. doi:10.1371/journal.pone. 0024846

Verkerke HP, Petri WA, Marie CS (2012) The dynamic interdependence of amebiasis, innate immunity, and undernutrition. Semin Immunopathol 34:771-785. doi:10.1007/s00281-012-0349-1

Von Bertalanffy L (1951) General system theory: a new approach to unity of science. Hum Biol 23:203-361

Westerberg AC, Henriksen C, Ellingvåg A et al (2010) First year growth among very low birth weight infants. Acta Paediatr 99:556-562. doi:10.1111/j.1651-2227.2009.01667.x

Westerberg AC, Schei R, Henriksen C et al (2011) Attention among very low birth weight infants following early supplementation with docosahexaenoic and arachidonic acid. Acta Paediatr 100:47-52. doi:10.1111/j.1651-2227.2010.01946.x

Wintergerst ES, Maggini S, Hornig DH (2007) Contribution of selected vitamins and trace elements to immune function. Ann Nutr Metab 51:301-323. doi:10.1159/000107673

Zhao L, Nicholson JK, Lu A et al (2012) Targeting the human genome-microbiome axis for drug discovery: inspirations from global systems biology and traditional Chinese medicine. J Proteome Res 11:3509-3519. doi:10.1021/pr3001628

Zimmermann MB, Kohrle J (2002) The impact of iron and selenium deficiencies on iodine and thyroid metabolism: biochemistry and relevance to public health. Thyroid 12:867-878

Zimmermann MB, Muthayya S, Moretti D et al (2006) Iron fortification reduces blood lead levels in children in Bangalore, India. Pediatrics 117:2014-2021. doi:10.1542/peds.2005-2440 